\title{
Oxygen Isotope Studies on the Origin of Tektites ${ }^{1}$
}

\author{
Hugh P. TAYLOR, JR. ${ }^{2}$ \\ Pennsylvania State University, University Park \\ SAMUEL EPSTEIN \\ California Institute of Technology, Pasadena
}

\begin{abstract}
O}^{\mathrm{rg}} / \mathrm{O}^{10}$ ratios of thirteen tektites from Czechoslovakia, Libya, Texas, Indochina, Philippine Islands, Australia, Java, and Peru have been determined by the fluorine-extraction technique. All but one of these lie in relatively restricted range of $0^{18} / 0^{10}$ ratio, with $\delta=9.6$ to 10.4 per mil relative to the ocean-water standard. Tektites are therefore 0.5 to $1.5 \mathrm{per}$ mil heavier than average granitic igneous rocks or about the same as average igneous quartz. The sample from Macusan, Peru $(\delta=12.0)$, is anomalous and is probably not a true tektite. Six analyzed shales are isotopically heavier than tektites and show a much wider range in values $(\delta=14.2,14.8,15.3,15.5,17.6,182)$. Several detrital sedimentary rocks previously analyzed by Silverman and the present authors have $\delta$ values of 10.2 to 15.5 ; analyzed metasedimentary rocks have $\delta$ values of 12.1 to 15.7 per mil. Therefore, tektites are not sedimentary or metasedimentary material fused by lightning or by impact of an astronomical body with the earth. Chemically, tektites are unlike terrestrial igneous rocks, and their oxygen isotopic composition is unlike that of sedimentary or metasedimentary rocks. They therefore may be extraterrestrial objects.
\end{abstract}

Introduction. The origin of tektites has been a subject of controversy for a number of years [Spencer, 1933; Barnes, 1940; Urey, 1957; O'Keefe, 1959; and others]. Some workers have suggested that they represent terrestrial silicate material fused by the impact of meteorites or comets upon the earth. The chemical composition of tektites is very similar to that of many ordinary argillaceous sedimentary rocks and their metamorphosed equivalents. These rocks, which include mudstone, siltstone, shale, slate, phyllite, pelitic schist, etc., are very common at the earth's surface; the probability of fusing such material by the chance impact of an extraterrestrial body with the earth is relatively great.

On the other hand, a number of workers have suggested that tektite glass is itself of extraterrestrial origin, possibly being derived from meteorite impact with the moon, or perhaps originating in some unknown manner elsewhere in the solar system or outside the solar system.

1 Mineral Industries Experiment Station Contribution 61-106. Contribution 1091, Division of Geological Sciences, California Institute of Technology, Pasadena, California.

2 Now at California Institute of Technology, Pasadena.
The recent work of Viste and Anders [1962], however, on the $\mathrm{Al}^{20}$ content of tektites suggests that an origin within the solar system is much more likely.

During the last few years, the writers have been carrying out an extensive study of the oxygen isotopic compositions of terrestrial rocks and minerals. In view of the controversy over the origin of tektites, it seemed advisable also to investigate the $0^{18} / 0^{10}$ ratios of some tektites. It was hoped that some valuable information might be obtained through a comparison of such results with oxygen isotope analyses of pelitic sedimentary or metasedimentary rocks.

The $0^{18} / 0^{10}$ ratios reported in this paper were determined in a sensitive mass spectrometer upon gas samples obtained by quantitatively reacting the silicate materials with fluorine at $450^{\circ} \mathrm{C}$ [Taylor and Epstein, 1962a]. The analyses are believed to be accurate to $\pm 0.2 \mathrm{per}$ mil relative to one another and to the Potsdam sandstone working standard. The results are reported in the familiar $\delta$ notation [e.g., see Epstein, 1959]:

$$
\delta=\left[\frac{R_{\text {sample }}}{R_{\text {teaderd }}}-1\right] 1000
$$

where $R_{\text {sample }}$ is $\mathrm{O}^{18} / \mathrm{O}^{16}$ in the sample and 
TABLE 1. Oxygen Isotopic Analyses of Tektites

\begin{tabular}{|c|c|c|c|}
\hline Sample & $\begin{array}{l}8 \mathrm{O}^{18} / \mathrm{O}^{18} \\
\text { per mil }\end{array}$ & $\begin{array}{l}\text { No. } \\
\text { of } \\
\text { Runs }\end{array}$ & $\begin{array}{l}\text { Average } \\
\text { Devi- } \\
\text { ation }\end{array}$ \\
\hline Java $\sharp 30-16$ & 9.6 & 2 & 0.2 \\
\hline $\begin{array}{l}\text { Bediasite \#27-17 } \\
\text { (Texas) }\end{array}$ & 9.6 & 2 & 0.2 \\
\hline $\begin{array}{l}\text { Indochinite \#40-15 } \\
\text { Australite-Charlotte }\end{array}$ & $\begin{array}{l}9.0 \\
9.7\end{array}$ & 2 & 0.2 \\
\hline Waters \#262 & 9.7 & 2 & 0.2 \\
\hline Australite $\# 97-2$ & 9.7 & 2 & 0.1 \\
\hline Java \#96-11 & 9.8 & 2 & 0.2 \\
\hline Philippinite \#156-105 & 10.1 & $\mathbf{1}$ & \\
\hline Indochinite \#42-2 & 10.2 & 2 & 0.0 \\
\hline $\begin{array}{l}\text { Libyan desert glass } \\
\qquad 43-5\end{array}$ & 10.2 & 3 & 0.1 \\
\hline Moldavite \#97-9 & 10.3 & 2 & 0.2 \\
\hline $\begin{array}{l}\text { Moldavite [Silverman, } \\
\text { 1951] }\end{array}$ & 10.4 & 2 & 0.5 \\
\hline $\begin{array}{l}\text { Philippinite [Silver- } \\
\text { man, 1951] } \\
\text { Macusan, Peru }\end{array}$ & $\begin{array}{l}10.4 \\
12.0\end{array}$ & $\begin{array}{l}2 \\
2\end{array}$ & $\begin{array}{l}0.0 \\
0.2\end{array}$ \\
\hline
\end{tabular}

The locations of most of these samples are more fully described by Friedman [1958]. Sample 30-16 was collected by G. H. R. van Konigswald from Trinil beds, central Java. Sample 156-105 was collected by Dr. J. Thorp 10 to 15 miles northeast of Manila, Philippine Islands.

$R_{\text {standare }}$ is $\mathrm{O}^{19} / \mathrm{O}^{18}$ in the standard. The standard used here is the ocean water analyzed by Silver$\operatorname{man}[1951]$; he obtained a $\delta$ value of +15.5 per mil for Potsdam sandstone on this scale. Our results have therefore also been adjusted to give a value of $\mathbf{1 5 . 5}$ for Potsdam sandstone, so that these data are reported relative to the standard commonly in use [Silverman, 1951; Clayton and Epstein, 1958; Taylor and Epstein, 1962a].

Experimental results. The only previous study of $0^{18} / \mathrm{O}^{10}$ ratios in tektites is that of Silverman [1951], who analyzed a philippinite and a moldavite. Values of 10.4 per mil were obtained for both. In the present study, oxygen isotope ratios were determined for nine tektites from various localities throughout the world, as well as for a sample of Libyan desert glass and an americanite from Macusan, Peru (Table 1). Except for the latter sample, all these $\delta$ values lie in the range 9.6 to 10.3 per mil, indicating that the $0^{18} / 0^{18}$ ratios of tektites are very similar, irrespective of age or geographic location.
The only differences which show up in the data are that moldavites appear to be relatively high in $0^{18}$ content, whereas the australites and javaites are relatively low. The total variation is small, however-not much greater than the experimental error.

Five oxygen isotope analyses of shales and one of an arkosic sandstone were made during the present study (Table 2). In addition, several sedimentary and metasedimentary rocks have been previously analyzed by Silverman [1951], Taylor and Epstein [1962a], and Taylor et al. [1962]. The $\mathrm{O}^{19} / \mathrm{O}^{18}$ ratios of these rocks are graphically tabulated in Figure 1, where a comparison is made with oxygen isotope data from tektites.

The sedimentary and metasedimentary rocks show a wide range in $0^{10} / \mathrm{O}^{10}$, from $\delta=10$ to $\delta=18$, a variation of 8 per mil. Each rock type shows a range of 4 to 5 per mil; undoubtedly, a greater range would be obtained if further analyses were made. These results contrast strongly with the $0^{19} / 0^{10}$ data obtained for tektites, both in terms of the total range of $0^{18} / 0^{10}$ involved and of the actual $0^{18} / 0^{10}$ ratios themselves.

Origin of tektites by impact melting of sedimentary rocks. The oxygen isotope results presented here clearly illustrate that tektites cannot simply be fused shales or pelitic schists. Their chemical compositions are perhaps compatible with such an origin [Barnes, 1940], but their $0^{19} / 0^{16}$ ratios are very definitely not. This conclusion contradicts the statements made by Silverman [1951] on this problem, which were based upon incomplete oxygen isotope data. Only if there were an accompanying oxygen isotope fractionation during the fusion process could the vast majority of sedimentary or metasedimentary rocks be made over into a composition similar to tektite glass. Inasmuch as such rocks must lose water during the very high temperatures of melting that are necessary to produce tektite glass [Friedman, 1958], it is probable that some changes in $0^{18} / 0^{10}$ do occur.

The water that would be expelled during fusion would almost certainly have an $0^{19} / 0^{10}$ ratio different from that of the rock. There is, however, no a priori reason to believe that the water would be isotopically heavier than the rock, which is necessary if one is to reduce the $\delta$ value of the rock into the tektite range. In this connection, it will be interesting to analyze 
TABLE 2. Oxygen Isotopic Analyses of Sedimentary Rocks

\begin{tabular}{ccc}
\hline \multicolumn{1}{c}{ Sample } & $\begin{array}{c}\delta 0^{18} / \mathrm{O}^{18}, \\
\text { per mil }\end{array}$ & $\begin{array}{c}\text { No. of } \\
\text { Runs }\end{array}$ \\
\hline $\begin{array}{c}\text { New Milford shale, Devonian, } \\
\text { Lanesboro, Pa., Wards \#47 }\end{array}$ & 14.2 & 1 \\
$\begin{array}{c}\text { Queenston shale, Ordovician, } \\
\text { Lewiston, N. Y., Wards \#27 }\end{array}$ & 17.6 & 1 \\
$\begin{array}{c}\text { Sodur shale, Silurian, Roches- } \\
\text { ter, N. Y. (Genese River }\end{array}$ & 14.8 & 1 \\
gorge) & & \\
$\begin{array}{c}\text { Keokuk shale, Missisgippian, } \\
\text { Crawfordsville, Indiana, }\end{array}$ & 15.3 & 1 \\
$\begin{array}{l}\text { Wards \#53 } \\
\text { Cretaceous shale-chip con- } \\
\text { glomerate, Harding Canyon } \\
\text { (N. fork), Santa Ana Mts., }\end{array}$ & & \\
$\begin{array}{l}\text { Calif. } \\
\text { (a) Shale clast }\end{array}$ & 18.2 & 1 \\
(b) Sandy arkosic matrix & 12.6 & 1 \\
\hline
\end{tabular}

some impactite glass and compare its $0^{19} / 0^{10}$ ratio with that of the original, unfused rock.

More compelling evidence on this question, however, is the great difference in total range of $0^{18} / 0^{10}$ for the tektites and for the terrestrial rocks. It is doubtful that during the fusion process these rocks would always lose exactly the proper amounts of $\mathrm{H}_{2} \mathrm{O}$ of the right $\mathrm{O}^{18} / \mathrm{O}^{16}$ ratio to bring their heterogeneous set of $\delta$ values down to the same narrow range of $0^{19} / 0^{10}$ that is found in tektites.
More studies will have to be made of $0^{18} / 0^{10}$ ratios in a wide variety of sedimentary rocks in order to see if there is by chance some particular clustering of $\delta$ values in a relatively narrow range. On the basis of existing data this seems unlikely, and it is also unlikely in view of our knowledge of the effect of authigenic mineral formation upon the $\delta$ values of rocks. It was first pointed out by Silverman [1951] that the greater the proportion of authigenic silica cement in a quartz sandstone, the higher the $0^{10} / 0^{10}$ ratio of the sandstone. This is reasonable because low-temperature authigenic silica (cherts, diatomites, etc.) is very rich in $\mathrm{O}^{19}$, with $\delta$ values of 28 to 36 per mil [Silverman, 1951; Engel et al., 1958]. This is a result of oxygen exchange with water; the fractionation factor is very large at low temperatures.

Hence, applying the same principle, any detrital igneous or metamorphic mineral will be much lower in $\mathrm{O}^{18}$ than the same mineral precipitated authigenically from sea water or during diagenesis. Minerals formed during weathering processes should be $0^{18}$-rich, because of exchange with surface waters. Sediments contain widely varying proportions of authigenic minerals and of minerals which have exchanged to some extent with coexisting waters; these minerals are of several different kinds. Therefore, it is likely that sediments all over the earth will show an extensive range in $\mathrm{O}^{18} / \mathrm{O}^{16}$, depending

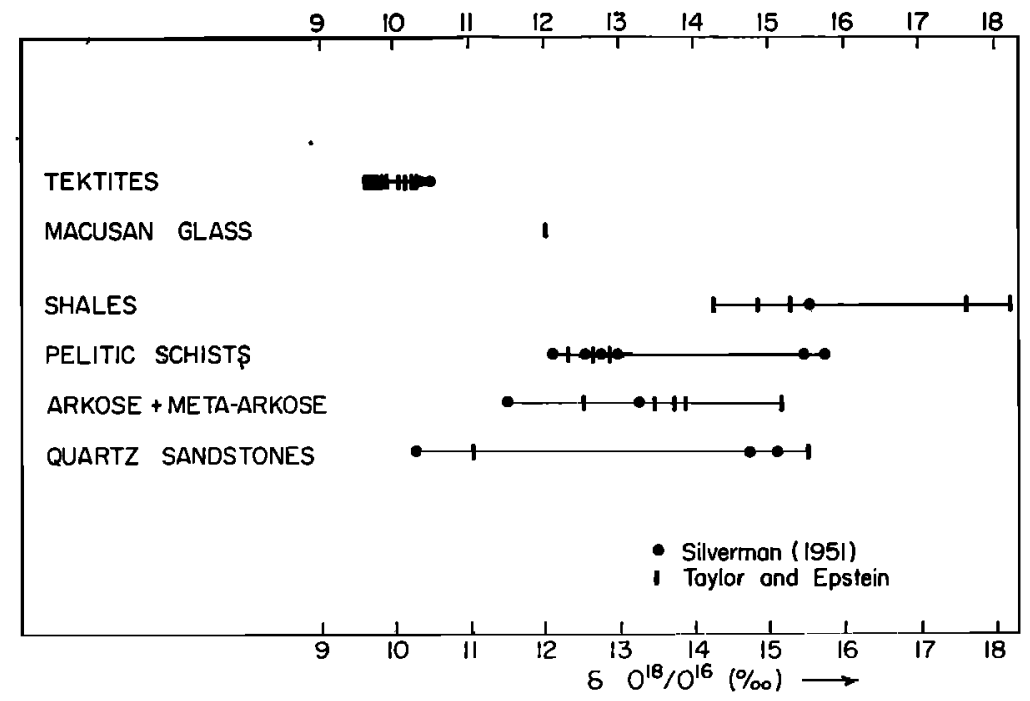

Fig. 1. Graphical tabulation of all oxygen isotopic analyses of tektites and of sedimentary rocks that can be related to the sea-water standard. 
upon the proportions and types of authigenic minerals added. Inasmuch as metamorphic minerals are generally richer in $\mathbf{O}^{10}$ than igneous minerals [Taylor and Epstein, 1962a; Taylor et al., 1962], there will be a significant variation in $0^{10} / 0^{10}$ even in the purely detrital minerals, depending upon their source areas.

The observations that sediments are much richer in $\mathrm{O}^{10}$ than igneous rocks and that they show a very wide range in $0^{18} / \mathrm{O}^{16}$ ratio are both explicable in terms of the above discussion. Metamorphosed sedimentary rocks also show a wide range in $\mathrm{O}^{18} / \mathrm{O}^{18}$, probably as a result of: (1) The $\delta$ value of the original, pre-metamorphic rock may influence the $0^{18} / 0^{10}$ ratio of the metamorphosed rock to a certain extent, depending upon the degree of oxygen exchange with coexisting pore fluids during metamorphism; and (2) the temperature of metamorphism and the kinds and proportions of metamorphic minerals present are all variables which will strongly influence the $0^{18} / \mathrm{O}^{10}$ ratio of the rock if any oxygen exchange with pore fluids occurs.

In summary, both the existing oxygen isotope data and our knowledge of the processes which bring about $0^{18} / 0^{16}$ variations in nature indicate that sediments and metasediments should show a wide range in $0^{18} / \mathrm{O}^{10}$ and should generally be significantly richer in $\mathrm{O}^{10}$ than tektites are. The fact that tektites of different ages from various widely scattered localities all have relatively similar $0^{18} / 0^{16}$ ratios seems to exclude an origin by impact melting of sedimentary or metasedimentary rocks. It is highly improbable, in view of the large range of $0^{18} / 0^{16}$ in terrestrial rocks, that a meteorite or comet would always strike rocks having the same oxygen isotopic composition.

Natural glasses of doubtful origin. The sample of glass from Macusan, Peru (Table 1), has a distinctly different $0^{18} / 0^{10}$ ratio from that of the known tektites. Many other properties of this glass are also aberrant [Friedman, 1958; Senftle and Thorpe, 1958], and the oxygen isotope data simply represent another line of evidence that this glass is not a true tektite. Its origin remains in doubt.

The sample of Libyan desert glass (Table 1) has an $0^{18} / 0^{10}$ ratio within the range of tektite compositions. This may be a coincidence, however, as Libyan desert glass, in contrast to the known tektites, is almost pure $\mathrm{SiO}_{2}$. It is inter- esting that the only widespread sedimentary rock which is likely to have a $\delta$ value similar to tektite glass is a pure quartz sandstone containing very little authigenic silica cement. This is because tektites have $0^{18} / \mathrm{O}^{18}$ ratios almost identical to the values found in quartz from igneous rocks [Taylor and Epstein, 1962a]. Inasmuch as relatively pure quartz sand is very abundant in the Libyan desert, the glass from that region could very easily be fused sand or sandstone. Therefore, the oxygen isotope data provide no evidence as to whether Libyan glass is an impactite or a true tektite.

Possible origins of tektites. In the light of the oxygen isotope data, the possible mechanisms of tektite formation appear to be reduced in number. It now seems likely that they must either be extraterrestrial objects or must be derived from a terrestrial rock type which has a restricted range of $\mathrm{O}^{18} / \mathrm{O}^{18}$. For example, granitic rocks commonly have $\delta$ values ranging from about 8.0 to 9.5 per mil relative to sea water, and gabbros generally lie in the range $\delta=6.0$ to 7.0 per mil [Taylor and Epstein, $1962 a$ ]. Therefore, if tektite glass is always derived from a certain type of igneous rock, its narrow $O^{18} / O^{10}$ variation is readily explained.

Only a very few of all the igneous rocks yet analyzed approach the tektites in chemical composition [Barnes, 1940]. These rocks are granitic types which are abnormally rich in $\mathrm{Fe}$ and $\mathrm{Mg}$, and somewhat richer in $\mathrm{SiO}_{2}$ than the average. Therefore, if tektites represent impact melting of the common terrestrial granitic rocks, there must have been a change in chemical composition of the rocks during melting. The alkalies $\mathrm{Na}$ and $\mathrm{K}$ must be preferentially fractionated off, and, inasmuch as tektites have higher $\mathrm{K} / \mathrm{Na}$ ratios than most granitic rocks (if one includes the very abundant quartz monzonites and granodiorites), more $\mathrm{Na}$ must be removed than $K$. None of these possibilities can be completely dismissed because these relatively volatile alkali metals might be vaporized and removed during the high temperatures involved in impact melting. In addition to these requirements of change in chemical composition, the $0^{10} / 0^{10}$ ratios of the fused materials would also have to be changed slightly, as the tektites average somewhat higher in $0^{18} / 0^{16}$ than granitic rocks. It must be added, however, that deeply weathered granitic rocks might 


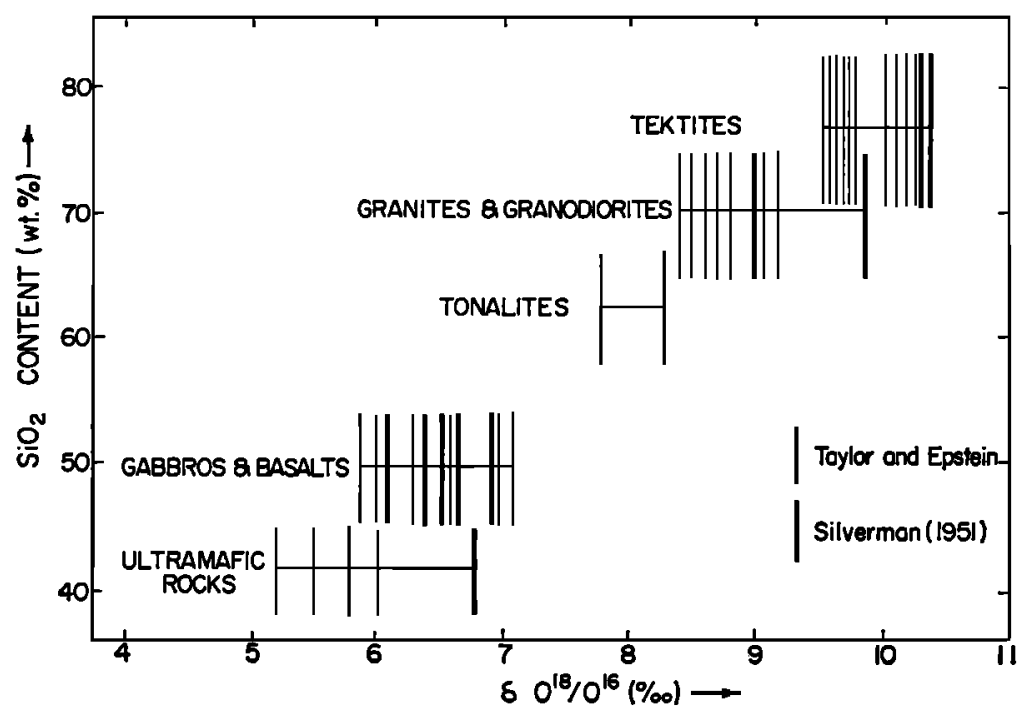

Fig. 2. Plot of all oxygen isotopic analyses of tektites and of igneous rocks that can be related to the sea-water standard versus the general range in $\mathrm{SiO}_{2}$ content for each rock type.

be expected to have higher $0^{18} / 0^{10}$ ratios than normal, because of the formation of $\mathrm{O}^{18}$-rich clay minerals by exchange with surface waters. No measurements have been made, but it is not unreasonable to hypothesize that $0^{19} / \mathrm{O}^{10}$ ratios of weathered granites and tektites might be very similar.

If the possibility is unacceptable that $0^{16} / 0^{16}$ ratios and chemical compositions would change in the correct direction and magnitude to produce materials of tektite composition from terrestrial rocks, tektite glass must be derived from an extraterrestrial source. The constancy of the $\mathrm{Sr}^{87} / \mathrm{Sr}^{89}$ ratio in tektites [Pinson et al., 1958], for example, would seem to argue against an origin by fusion of granitic rocks. The oxygen isotope data give no information concerning any source outside the earth, as we have no knowledge about the $0^{19} / 0^{16}$ ratios of any definitely extraterrestrial bodies except meteorites.

It is possible to speculate on one aspect of the oxygen isotope data which suggests that tektites may have originated through igneous processes. First, as was stated by Barnes [1940], a few terrestrial igneous rocks are similar in chemical composition to that of tektite glass; therefore, magmatic processes clearly can, in certain instances at least, yield $\mathrm{SiO}_{\mathbf{2}}$-rich fractions similar to tektite glass. Second, it is interesting to note the relationship between the $\mathrm{O}^{10} / \mathrm{O}^{10}$ ratios and $\mathrm{SiO}_{2}$ contents of terrestrial igneous rocks, for comparison with those of the tektites (Figure 2). Here are plotted all available oxygen isotopic analyses of igneous rocks that can be related to the sea-water standard [Silverman, 1951; Taylor and Epstein, 1962a]. As we do not have exact chemical analyses of all these rocks, their $\mathrm{SiO}_{2}$ contents are not accurately known. Therefore, the 'normal' range of $\mathrm{SiO}_{2}$ variation in each rock type is used instead, based upon the known analyses, estimates of chemical compositions from modal analyses, and chemical analyses of similar rocks from the literature. It is believed that the actual $\mathrm{SiO}_{2}$ contents of the rocks shown plot well within the respective ranges indicated. Tektites appear to plot very nicely on the igneous-rock trend.

Not only do tektites seem to fit on the same trend as igneous rocks in terms of $\mathrm{SiO}_{2}$ content and $0^{18} / O^{16}$ ratio, but a finer distinction of the same type is noticeable within the tektite group itself. The relatively $\mathrm{SiO}_{2}$-rich moldavites [Barnes, 1940] have consistently higher $0^{19} / 0^{10}$ ratios than the other tektites, whereas the australites and javaites, which are lower in $\mathrm{SiO}_{2}$ content [Barnes, 1940], have the smallest $\mathrm{O}^{18}$ / $\mathrm{O}^{10}$ ratios.

Insofar as the igneous rocks are concerned, the observed trends in $0^{18} / 0^{16}$ ratio versus $\mathrm{SiO}_{2}$ content are thought to result from the particular tendency of each rock type to incor- 
porate $0^{18}$ relative to $0^{18}$ during oxygen exchange at high temperatures [Taylor and Epstein, 1962a]. It is shown by Taylor and Epstein [1962b] that the various coexisting minerals within a rock also tend to concentrate $0^{18}$ roughly in porportion to their $\mathrm{SiO}_{2}$ content, whether they are from igneous rocks or metamorphic rocks. This is apparently a result of a tendency toward oxygen isotopic equilibrium among these coexisting minerals.

Stony meteorites, which are chemically and mineralogically similar to ultramafic rocks, also have $O^{19} / 0^{10}$ ratios that are very similar to those of the ultramafic rocks [Silverman, 1951; Vinogradov et al., 1958]. It is therefore perhaps not unreasonable to hypothesize that most ultramafic materials within the solar system might also have similar $0^{18} / 0^{10}$ ratios. Therefore, if tektite material originates by some igneous process within the solar system, and if it is able to exchange oxygen at high temperatures with silicate material which in mineralogical, chemical, and oxygen isotopic composition is similar to one of the major igneous rock types of the earth, then it is perfectly conceivable that the tektites would attain $\delta$ values similar to those shown in Figure 2.

Both the occurrence of tektites and the observation that they must have formed at exceedingly high temperatures imply that tektite glass is not formed by a terrestrial igneous process. Their relationship to igneous rocks, as shown by their $0^{13} / 0^{10}$ ratios, suggests that they probably form through extraterrestrial igneous processes or by impact of meteorites or comets with terrestrial igneous rocks. ${ }^{3}$ If the latter occurs, significant changes in chemical and oxygen isotopic composition must occur during fusion, and these must always be of a similar direction and magnitude. If the former occurs, it seems likely that the material is fused and ejected from its extraterrestrial source by meteorite impact [Chao et al., 1962].

Acknowledgments. We are indebted to Dr. Irving Friedman, who provided most of the tektite samples analyzed. Discussions with Dr. G. J. Wasserburg have proved to be very valuable.

${ }^{3}$ After the completion of the present work, a paper by H. P. Schwarcz, euggesting that tektites may be fused soils, appeared in the April 7, 1962, issue of Nature. It will be interesting to analyze some soils to see if they show a narrow range of $\mathrm{O}^{18} / \mathrm{O}^{10}$.
This work was supported by the Atomic Energy Commission, contract AT (11-1)-208.

\section{REFERENCES}

Barnes, V. E., North American tektites, Texas Univ. Publ. $3945,477,1940$.

Chao, E. C. T., I. Adler, E. J. Dwornik, and J. Littler, Metallic spherules in tektites from Isabela, Philippine Islands, Science, 185, 97, 1962.

Clayton, R. N., and S. Epstein, The relationship between $0^{18} / \mathrm{O}^{10}$ ratios in coexisting quartz, carbonate, and iron oxides from various geological deposits, J. Geol., 66, 352, 1958.

Engel, A. E. J., R. N. Clayton, and S. Epstein, Variations in isotopic composition of oxygen and carbon in Leadville limestone (Mississippian, Colorado) and in its hydrothermal and metamorphic phases, J. Geol., 66, 375, 1958.

Epstein, S., The variations of the $0^{18} / O^{10}$ ratio in nature and some geologic applications, in $R e-$ searches in Geochemistry, p. 217, edited by $P$. H. Abelson, John Wiley \& Sons, New York, 1959.

Friedman, I., The water, deuterium, gas, and uranium content of tektites, Geochim. et Cosmochim. Acta, 14, 316, 1958.

O'Keefe, J. A., Origin of tektites, Science, 190, 97, 1959 .

Pinson, W. W., Jr., L. F. Herzog, A. W. Fairbairn, and R. F. Cormier, $\mathrm{Sr} / \mathrm{Rb}$ age study of tektites, Geochim. et Cosmochim. Acta, 14, $331,1958$.

Senftle, F. E., and A. Thorpe, Magnetic susceptibility of tektites and some other glasses, Geochim. et Cosmochim. Acta, 14, 234, 1958.

Silverman, S. R., The isotope geology of oxygen, Geochim. et Cosmochim. Acta, \&, 26, 1951.

Spencer, L. J., Origin of tektites, Nature, 181, $117,1933$.

Taylor, H. P., Jr., A. L. Albee, and S. Epstein, $\mathrm{O}^{18} / \mathrm{O}^{10}$ ratios in coexisting minerals of three assemblages of kyanite-zone pelitic schist, $J$. Geol., in press, 1962.

Taylor, H. P., Jr., and S. Epstein, Relationship between $\mathrm{O}^{18} / \mathrm{O}^{16}$ ratios in coexisting minerals of igneous and metamorphic rocks, 1, Principles and experimental results, Bull. Geol. Soc. Am., $7 \$, 461,1962 a$.

Taylor, H. P., Jr., and S. Epstein, Relationship between $\mathrm{O}^{18} / \mathrm{O}^{16}$ ratios in coexisting minerals of igneous and metamorphic rocks, 2, Application to petrologic problems, Bull. Geol. Soc. Am., $79,675,1962 b$.

Urey, H. C., Origin of tektites, Nature, 179, 557, 1957.

Vinogradov, A. P., E. I. Dontsova, and M. S. Chupakhin, The isotopic composition of oxygen in igneous rocks and meteorites, Geokhimiya, no. 3, 187, 1958.

Viste, E., and E. Anders, Cosmic-ray exposure history of tektites (abstract), J. Geophys. Research, 67, 1661, 1962.

(Manuscript received May 5, 1962.) 